\title{
WEBQUEST E A CONSTRUÇÃO DE LEITORES- AUTORES NA ERA DIGITAL
}

\author{
Denise Salim Santos (UERJ) \\ Rafaela Capitanio Zanoni (UERJ)
}

Resumo: A WebQuest, tecnologia educacional criada por Bernie Dodge em 1995, pode estimular a aquisição de letramentos digitais durante a formação básica, promovendo o uso da leitura e da escrita no ciberespaço e atuando na construção de cidadãos críticos multiletrados que consigam se posicionar, de modo consciente e construtivo, em diversas esferas. Segundo seu criador, essa metodologia é vantajosa, por ser acessível e sem custos aos docentes e à escola, e pode transformar o ambiente de ensino tradicional em um contexto mais dinâmico e estimulante ao aprendizado. Sendo assim, este estudo tem por objetivo verificar a aplicabilidade dessa ferramenta no ensino de Língua Portuguesa. Concluímos, então, que é preciso rever como as Novas Tecnologias da Informação e Comunicação (NTICs) são inseridas em sala de aula, pois se elas não conseguirem fazer com que o aluno transforme a informação em conhecimento aplicado não estarão cumprindo adequadamente a sua função educacional.

Palavras-Chave: Letramento digital; WebQuest; Escrita e leitura.

Abstract: WebQuest, educational tecnology created by Bernie Dodge in 1995, can stimulate the acquisition of digital literacy during basic schooling, promoting the use of Reading and writing in cyberspace and acting in building critical multi-literate citizens who are able to posion themselves conciously and constructively in various spheres. According to its creator, this methodology is advantageous because it is accessible and without costs to the teachers and the school and can transform the traditional teaching environment into a more dynamic and stimulating learning environment. Therefore, this study aims to verify the applicability of this tool in the teaching of Portuguese Language. It was concluded, therefore, that it is necessary to review how the New Technologies of Information and Communication (NICTs) are inserted in the classroom, because if they can not get the student to turn information into applied knowledge, are not adequately fulfilling their educational function.

Keywords: Digital literacy; WebQuest; Writing and reading 


\section{INTRODUÇÃO}

O processo de globalização permitiu que as tecnologias se modificassem no decorrer das últimas décadas e, assim, as mudanças sociais foram inevitáveis. Atualmente a internet vem ganhando cada vez mais espaço por meio de suas inúmeras ferramentas de pesquisa e de aquisição de conhecimento e nos leva à reflexão de que as práticas em sala de aula necessitam ser repensadas e reavaliadas com urgência.

A aprendizagem da Língua Portuguesa é de bastante relevância na educação formativa, proporcionando troca de experiências, conhecimentos, leituras e visões de mundo, funcionando como um meio de comunicação e acesso aos mais variados modos de agir e interagir socialmente, pensar, sentir e enxergar a realidade. $O$ conhecimento encontrase no ciberespaço e nos ambientes virtuais, colocando leitura, escrita e informática em um mesmo plano. Logo, a participação social é importante para que um indivíduo possa dominar a língua, pois é pela interação que o homem se comunica, se expressa e defende pontos de vista acerca dos mais variados assuntos, tem acesso às mais diversas informações e constrói suas visões de mundo.

Então, trabalhar com o ensino de Língua Portuguesa, em distintos cursos e níveis, é inserir os estudantes em práticas sociais, a fim de levá-los à reflexão sobre a maneira 
de produção de textos e ao modo como esses textos circulam nas diversas esferas da sociedade. Além disso, estudar a língua portuguesa por meio de diversificados gêneros discursivos possibilita ao aluno a aproximação com outras culturas, o que faz com que ele compreenda a sua identidade e a sua própria cultura. Desse modo, a escola tem o papel preponderante de criar um espaço de interação do conhecimento sistematizado, proporcionando aos alunos condições de aprendizagem que ultrapassem o ensino das letras e dos códigos, mas direcionando-os para a solução de situações de conflito de diversas esferas.

Nesse contexto, percebemos que a contemporaneidade tem mostrado a existência de inúmeros letramentos e que precisamos rever a maneira tradicional como se tem trabalhado junto aos alunos, a fim de prepará-los para um mundo mais dinâmico, rápido e digital.

A cibercultura tem sido muito importante nesse processo de construção dos letramentos digitais e na formação de cidadãos críticos, letrados, criativos, inovadores, autônomos, flexíveis, que saibam solucionar conflitos, sendo colaborativos, trabalhando em equipe e sempre dispostos a aprender. Pensando em colaborar para o desenvolvimento de indivíduos letrados, principalmente no que diz respeito 
ao aspecto digital, vemos que as Novas Tecnologias de Informação e Comunicação (NTICs) se configuraram como técnicas bastante úteis e produtivas para o ensino de Língua Portuguesa por meio de mecanismos da Internet.

A WebQuest é uma dessas ferramentas, pois Abar e Barbosa (2008, p.11) veem-na como "uma atividade didática, estruturada de forma que os alunos se envolvam no desenvolvimento de uma tarefa de investigação usando principalmente recursos da Internet". Tal metodologia de aprendizagem não exige que o professor tenha conhecimentos de programação para ter um bom desempenho empregando essa ferramenta, pois basta um simples editor de texto para que ele organize o material e os objetivos de sua proposta. Além disso, a publicação do conteúdo no ciberespaço pode ocorrer de maneira gratuita, o que facilita bastante a vida das escolas que não têm condições de arcar com o investimento em um programa, por exemplo.

\section{TECNOLOGIA E APRENDIZAGEM: UM PERCURSO POSSÍVEL}

O termo tecnologia é antigo e surgiu bem antes de pensarmos em máquinas elétricas ou equipamentos ultramodernos. Kenski (2012) destaca que o conceito de tecnologias tem a ver com a quantidade de coisas que o 
nosso cérebro é capaz de criar, independente da época e da sua maneira de uso. De acordo com a autora, a linguagem, por exemplo, é uma espécie de tecnologia, mesmo que não se apresente no formato de um equipamento, pois ela foi criada para permitir o processo comunicacional entre indivíduos de um grupo social. Logo, a tecnologia linguagem foi organizada por seu próprio uso e se transformou ao longo das infinitas relações sociais, possibilitando o surgimento de vários idiomas que caracterizam a cultura de um povo.

De acordo com Kenski (2012, p.15), “desde o início dos tempos, o domínio de determinados tipos de tecnologias, assim como o domínio de certas informações distinguem os seres humanos", ressaltando as relações de poder existentes entre os indivíduos que possuem uma tecnologia ou um conhecimento acerca de um objeto tecnológico. Para essa autora, as NTICS, a partir do momento em que se espalham pela sociedade, modificam as exigências profissionais e o modo como os indivíduos vivem e se comunicam com outros. Essas novas tecnologias estão em constante modificação, utilizam o espaço virtual e a matéria-prima essencial é a informação.

Segundo Ribeiro (2012), as pessoas vão adquirindo novas tecnologias e modificam seus usos, emergindo maneiras 
diferentes de se comportar, de se comunicar e até mesmo capacidades que tomam outras proporções, conforme os indivíduos tenham acesso a novos instrumentos e aprendam outros meios de fazer as coisas acontecerem. Para essa autora, "as tecnologias não precisam ser encaradas como ameaças, mas como novos meios de fazer, de propor e, por que não, de seduzir, tanto alunos quanto professores" (RIBEIRO, 2012, p.29).

A partir desse momento, utilizaremos os estudos de Kenski (2012) para falarmos sobre tecnologia. Os avanços tecnológicos das últimas décadas produziram a transformação das TICs (Tecnologias da Informação e Comunicação) em NTICs (Novas Tecnologias da Informação e Comunicação), já que o fluxo de informações passou a ocorrer de maneira mais veloz, garantindo uma comunicação, muitas vezes, instantânea.

Ao falarmos em ambientes digitais, percebemos que os hipertextos e hipermídias transformaram os meios como acessávamos as informações. Kenski (2012, p.32) nos traz uma definição bastante adequada para esses conceitos, considerando o hipertexto como "uma evolução do texto linear na forma como o conhecemos" e a hipermídia como algo que aparece nesse encadeamento de textos e que 
tem relação com as mídias (fotos, vídeos, sons). Logo, essa linguagem digital que surge a partir das inúmeras NTICs determina as mudanças nas formas de acesso à cultura, lazer e informações.

O hipertexto possibilita ir-se de um texto a outro, de apenas um ponto de vista a múltiplos olhares, por meio do processo de "lincagem" que os ambientes digitais proporcionam ao leitor. Ainda para esse autor, a hipermídia constitui um aglomerado de mídias, como "imagens visuais, som, vídeo e animação" que trazem conteúdos repletos de informação ao leitor/usuário. Lemke ressalta:

O texto [escrito] pode ou não ser a espinha dorsal de uma obra multimídia. O que realmente precisamos ensinar, e entender antes de poder ensinar, é como diferentes letramentos, diversas tradições culturais combinam essas diferentes modalidades semióticas para produzir significados que são mais do que a somatória do que cada uma delas pode significar em separado. (LEMKE, 1998 Apud ROJO, 2013, p.22)

As NTICs não são somente apoio para a tecnologia em si, "elas têm suas próprias lógicas, suas linguagens e maneiras particulares de comunicar-se com as capacidades perceptivas, emocionais, cognitivas, intuitivas e comunicativas das pessoas" (KENSKI, 2012, p.38), ou seja, as NTICs surgiram para transformar a era digital a partir de características 
bem particulares. A rapidez com que as informações se modificam faz com que a nossa atualização seja um processo constante. Dessa forma, a busca por informações mais atuais e relevantes torna-se imprescindível na vida atual.

A tecnologia é um recurso enriquecedor para promover o desenvolvimento de uma educação mais eficaz, além de possibilitar a integração dos aspectos individual e social do indivíduo. É fato a existência de uma relação direta entre educação e tecnologias, já que a primeira é extremamente necessária para aprender-se mais sobre as tecnologias e as opções tecnológicas permitem o acesso ao conhecimento de forma dinâmica e instantânea.

\section{LEITURA E ESCRITA EM AMBIENTE DIGITAL}

A inclusão das tecnologias digitais no dia a dia possibilitou muitas modificações no processo de comunicação e interação dos indivíduos. Hoje, a leitura e a escrita reúnem textos híbridos que utilizam variadas semioses, e a escola passa a ter uma grande responsabilidade na formação leitora do século XXI. Já não basta desenvolvermos uma pedagogia que priorize o letramento das mídias impressas, uma vez que estamos diante de novos tempos e de multiletramentos, de acordo com Coscarelli (2016). Os professores de Língua Portuguesa devem preparar os alunos para lerem textos com as mais diversificadas mídias, assim como para produzirem textos multimodais. 
Cabe destacar aqui que os novos letramentos só são perfeitos se envolverem duas perspectivas: a técnica e o ethos. A parte técnica, ou digitalidade, se refere ao que o computador nos possibilita nos dias atuais, como uma infinitude de transformações e combinações com textos verbais, não verbais, sons. Já o ethos significa uma nova mentalidade que resulta em novas formas de fazer. Segundo Rojo (2013), os novos letramentos são "mais 'participativos', 'colaborativos' e 'distribuídos' do que os letramentos convencionais. Ou seja, eles são menos 'publicados', 'individualizados' e 'centralizados no autor'”, e ainda nos mostram que enxergá-los dessa forma é resultado do advento da concepção da Web 2.0, pois ela

assume que o mundo contemporâneo é
diferente em aspectos importantes do que
era há trinta anos e que essa diferença
está crescendo. Muito dessa mudança se
relaciona ao desenvolvimento de novas
tecnologias interconectadas, a novas
maneiras de fazer coisas e a novas maneiras
de ser possibilitadas por essas tecnologias.
(ROJO, 2013, p.179)

Para ler um texto, os leitores precisam identificar letras e sons, construir sílabas e palavras, compreender o que as palavras significam dentro do contexto e entender textos que fazem parte de todos os tipos e gêneros. 
Um leitor fluente mantém o interesse por toda a leitura, possui conhecimentos de mundo e linguísticos prévios, ativa mecanismos metacognitivos para fazer predições e inferências. É importante lembrar que a leitura geralmente ocorre em uma situação de comunicação (onde existe um autor, um leitor, o texto e um contexto) e por esse motivo devemos levar em consideração o contexto social onde a leitura acontece e as experiências de vida do leitor. Coscarelli (2016, p. 69) destaca que "cada ato de leitura é diferente e requer que o texto seja abordado de formas diferentes" e "cada leitor traz para a leitura seus próprios objetivos, sua motivação, seus interesses, ideias e experiências".

Se é desejo incluir os letramentos digitais no contexto escolar, deve-se estimular os leitores a utilizarem seus novos costumes de leitura dentro da escola, pois cada vez mais os textos verbais recebem uma série de animações, sons, imagens estáticas e/ou em movimento, uma multiplicidade de cores e leiautes.

Coscarelli (2016) defende que a hipertextualidade está presente em todos os ambientes, sejam eles impressos ou digitais, uma vez que realizamos várias associações durante o processo leitor, relacionando palavras, situações, imagens e contextos. Logo, para aprender a escrever ou para ler, 
as pessoas ativam suas capacidades associativas a todo instante a fim de obter situações produtoras de sentido. A autora ainda destaca que não existe diferença entre competências para ler em meio impresso ou digital. O que acontece é que o ambiente digital às vezes exige uma capacidade de leitura já existente de forma mais abrangente que no meio impresso.

A pesquisadora apresenta três habilidades para um leitor ser bem-sucedido em sua leitura, independentemente do suporte em que o texto foi produzido. A primeira questão é saber buscar as informações; a segunda, é estabelecer as ligações entre as linguagens verbais e as não verbais; e a terceira constitui a maneira como utilizamos as informações.

Embora a leitura no ciberespaço possa ser vista como um processo leitor qualquer, faz-se importante destacar que a leitura na internet inclui habilidades de navegação específicas. Para Azevedo (2013, p.101), o período de navegação relaciona-se "à busca de informação e às estratégias que o leitor/usuário desenvolve para explorar e manter-se localizado no conteúdo (o que não deixa de ser uma camada, embora mais superficial, da leitura)".

A autora também informa que a navegação digital exige algumas habilidades: verificar os meios de pesquisa e saber 
utilizá-los; escolher as mais apropriadas palavras-chave; analisar se a informação encontrada condiz com o objetivo da pesquisa; examinar os elementos gráficos que indicam a presença de um link; dominar as camadas do hipertexto e fazer inferências sobre o assunto a partir do link; escolher conteúdos compatíveis com o objetivo da leitura; relacionar o link ao conteúdo.

Portanto, vemos que navegar na esfera digital não é um processo simples, pois exige todas essas habilidades do leitor e a estratégia de ensino WebQuest cumpre a função de desenvolver todas essas aptidões. Com isso, depreendemos que um leitor competente deve adquirir capacidades que Ihe permitam navegar tanto no que está impresso quanto no que está nas telinhas.

Desse modo, de acordo com Coscarelli (2016, p.28), o desenvolvimento de letramentos digitais vai muito além de apresentar aos alunos os gêneros e mídias encontrados no ciberespaço, pois "a leitura no ambiente digital inclui controlar os propósitos de leitura, buscar, selecionar, interpretar e contrastar informações", utilizando a informação obtida para a resolução de problemas complexos presentes no cotidiano deles, atendendo às expectativas desse século. 


\section{WEBQUEST : UMA ATIVIDADE COOPERATIVA}

De acordo com as diretrizes de Dodge (1995, Apud ROCHA, 2007, p.74), criador da metodologia educacional em questão, a WebQuest tem como objetivo o envolvimento de alunos e professores no uso da Internet para fins educacionais, "estimulando a pesquisa, o pensamento crítico, o desenvolvimento de professores e a produção de materiais". Dodge (1995) estabelece como requisito primordial que todos os recursos utilizados em uma WebQuest sejam provenientes da internet.

Para Rocha (2007, p.59) o conceito de WebQuest surge da necessidade "de tornar os aprendizes agentes ativos do processo do ensino-aprendizagem, tirando do professor a imagem da única fonte detentora do conhecimento em sala de aula" e, para Abar e Barbosa (2008), a WebQuest é

uma metodologia de ensino na qual o aluno se envolve em uma investigação, utilizando preferencialmente recursos da internet, para resolver um problema significativo. Baseia-se em princípios de aprendizagem colaborativa e procura ativar competências intelectuais mais complexas e exigentes que a tradicional armazenagem de conteúdos. (p.14)

O emprego dessa ferramenta no ensino de Língua Portuguesa tem por objetivo fazer com que os alunos se 
tornem construtores do próprio conhecimento e, ainda, estimular os professores a tornar o ensino mais próximo da realidade e/ou vivência dos estudantes. Abar e Barbosa (2008, p.13) afirmam que

um ambiente de aprendizagem favorável às nossas aspirações deve proporcionar uma aprendizagem colaborativa e cooperativa, incentivar a investigação e o pensamento crítico, oferecer atividades para estimular uma área cognitiva de nível mais elevado, exigindo reflexão, análise, síntese e avaliação, além de aumentar as competências sociais e a autoestima do aluno.

Ao elaborar uma WebQuest é necessário observar alguns princípios básicos: entender que a aprendizagem é cooperativa, ou seja, "além da interação e colaboração, há interdependência positiva e responsabilidade individual" (ABAR E BARBOSA, 2008, p.13) e considerar na elaboração a transformação das informações, pois o indivíduo só aprende quando é capaz de transformar a informação em algo que faça sentido.

Uma WebQuest é composta por uma página da Web, criada pelo próprio professor com a finalidade de apresentar aos alunos uma tarefa investigativa, baseada em conhecimentos e conteúdos programáticos que foram ou não trabalhados em sala de aula. O objetivo essencial dessa 
atividade é fazer uma aproximação do tema à realidade do aluno, "onde a pesquisa é orientada com base em websites previamente selecionados pelo professor (mas não somente neles) e desenvolvida com base em roteiros elaborados pelo professor" (ROCHA, 2007, p.60), estimulando o aluno a construir o próprio conhecimento. Na opinião de Silva (2008, p.82), a WebQuest pode "tornar-se uma ferramenta auxiliar para o professor na elaboração de tarefas motivadoras para os aprendizes, tornando-os elementos ativos na construção do seu próprio conhecimento".

A utilização dessa metodologia se justifica pela grande adaptabilidade de uso e pelo trabalho em equipe. Percebemos que a WebQuest se amolda a diversas situações e contextos, tendo em vista que pode ser utilizada em qualquer ano e em qualquer nível de ensino, independe da faixa etária do aluno, pode tratar de qualquer assunto e, ainda, pode ser multidisciplinar. Dodge (1995, Apud ROCHA, 2007, p.60) reitera a importância da aprendizagem interativa e colaborativa, afirmando que esse tipo de aprendizagem é mais eficaz, pois "as WebQuests estão fundadas na convicção de que aprendemos mais e melhor com os outros, não individualmente. Aprendizagens mais significativas são resultados de atos de cooperação". Daí a justificativa para sua presença no planejamento das atividades escolares. 
Para Dodge (2002, Apud CEGARRA, 2007, p.86, tradução nossa), "Todo este trabalho colaborativo deve estar baseado em uma estrutura para ajudar os alunos na construção de sua aprendizagem)"1 ${ }^{1}$, pois, se o docente não tiver uma base sólida a respeito da tecnologia e do processo construtivista, o aluno estará navegando na internet sem um objetivo específico e não conseguirá transformar as informações em conhecimento.

Dodge (1995) desenvolveu sua metodologia de ensino baseado na distribuição das atividades propostas de maneira clara, objetiva e organizada, capaz de fazer com que o aluno se localize nas atividades a qualquer momento. Para o idealizador, a WebQuest deve ser dividida em sete partes: Introdução, Tarefa, Processo, Recursos, Avaliação, Conclusão e Créditos. Com o decorrer do tempo, as etapas Processo e Recursos se unificaram, já que uma é relacionada à outra, conforme veremos adiante.

Toda essa estrutura pode ser justificada, pois tal modelo de tecnologia educacional assemelha-se a um projeto, que na realidade surge a partir de uma ideia. Na WebQuest, a fase de idealização pode ser representada pela "Introdução". Em seguida, os objetivos do projeto são estabelecidos, ou seja, a "Tarefa" é apresentada. Posteriormente, cria-se um "plano

$1[\ldots]$ "todo este trabajo colaborativo debe estar apoyado em uma estrutura para ayudar a los alumnos a construir su aprendizaje" (Cegarra, 2007, p.86). 
de ações que devem ser executadas, os recursos e fontes necessárias à execução dessas ações", que representam os itens "Processo" e "Recursos". Na fase seguinte, temos a avaliação do projeto no item "Avaliação" e os resultados alcançados na "Conclusão". O item "Créditos" fornece informações de referências utilizadas e contatos do produtor.

A seguir, apresentaremos uma proposta de ensino de Língua Portuguesa elaborada pelas autoras deste artigo, cujo tema é a Estilística e a Publicidade. Essa WebQuest foi criada para ilustrar a composição de cada etapa dessa ferramenta.

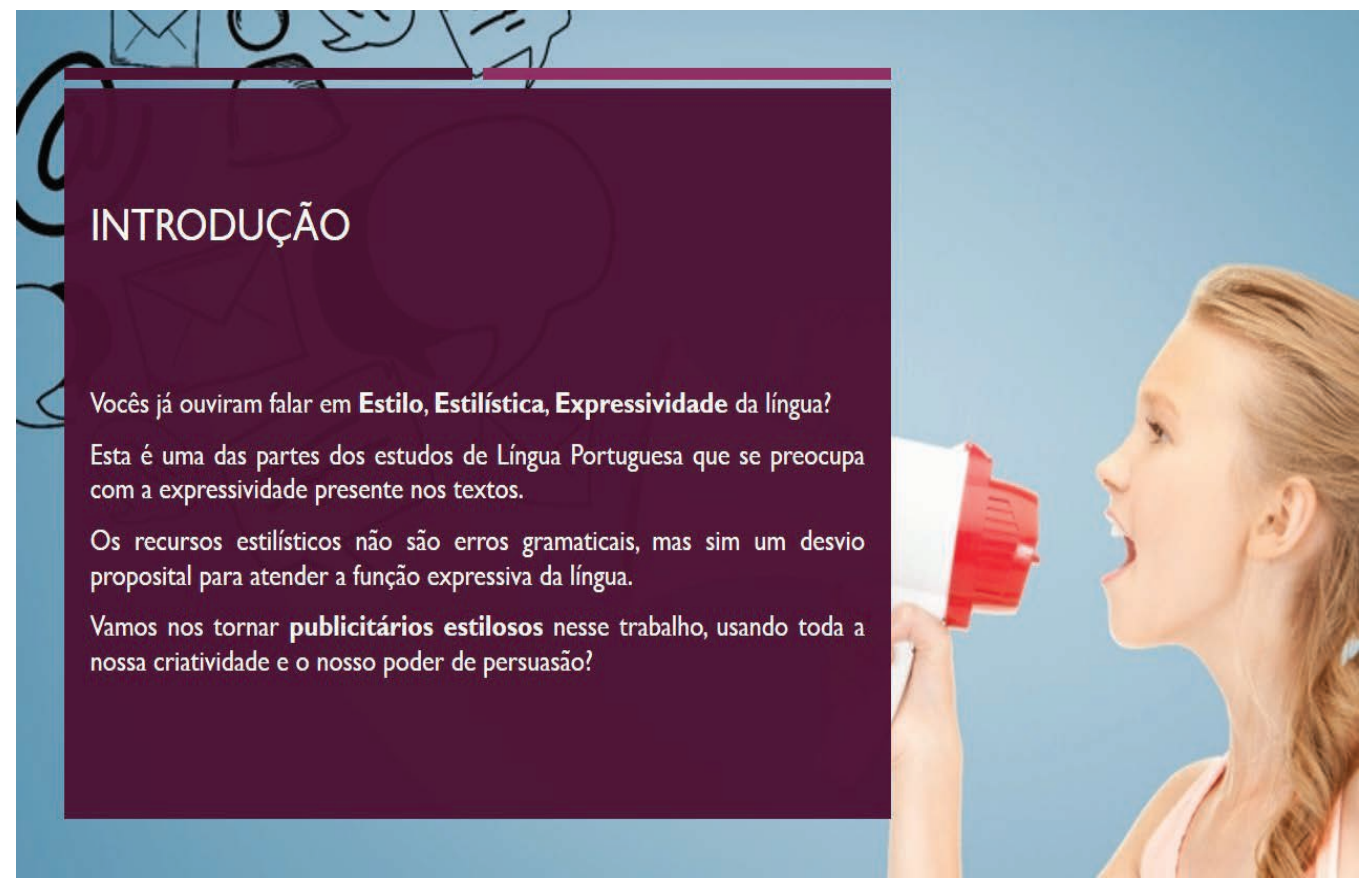

FIGURA 1 - Modelo de Introdução (Fonte: ZANONI, R.C, 2018) 


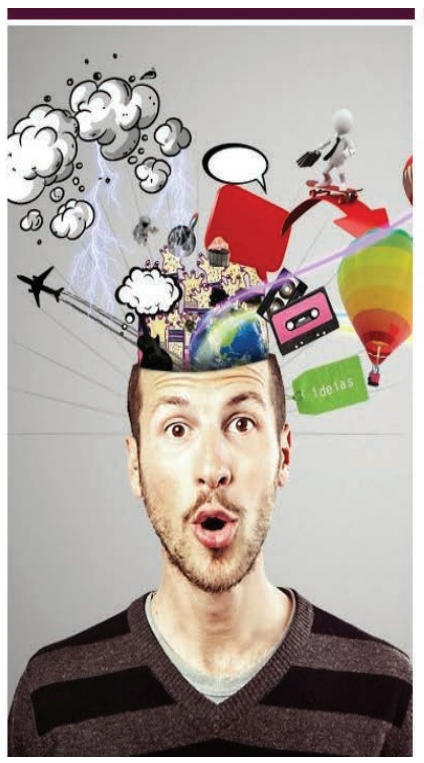

\section{TAREFA}

Vocês deverão se dividir em grupos de até 4 alunos para conhecer os desafios que a Estilística tem a nos oferecer!

Cada grupo deverá produzir um anúncio publicitário escrito para divulgar um produto.

E agora? O que é um anúncio publicitário? Como elaborar um anúncio publicitário? Quais recursos estilísticos ajudam na construção de uma publicidade?

\section{Não se preocupem com essas e outras questões, pois vocês receberão as orientações na próxima página.}

A partir de agora vocês são publicitários! Usem a criatividade para elaborar uma publicidade atrativa e persuasiva!

FIGURA 2 - Modelo de Tarefa (Fonte: ZANONI, R.C, 2018)

\section{PROCESSO E RECURSOS}

I ${ }^{\circ}$ passo: Vocês aprenderão a diferença entre publicidade, propaganda e marketing em:

http://guiadoestudante.abril.com.br/profissoes/publicidade-epropaganda

$2^{\circ}$ passo: Os links abaixo devem ser acessados para que vocês entendam os procedimentos necessários para a criação de um anúncio publicitário. Leiam com atenção!

http://www.sigmaquadrado.com/newsletter/arquivo/comofazerumanunci opublicitariodesucesso.html

https://www.estudokids.com.br/anuncio-publicitário/

http://brasilescola.uol.com.br/redação/anuncio-publicitário.htm

https://www.todamateria.com.br/linguagem-publicitaria/

$3^{\circ}$ passo: Agora vamos estudar um pouquinho os recursos estilisticos..

http://português.uol.com.br/gramatica/conceito-estilística.html

http://mundoeducacao.bol.uol.com.br/gramatica/figuras-linguagem3.htm http://www.figuradelinguagem.com/

https://rachacuca.com.br/educação/português/figuras-de-linguagem/

http://www.soportugues.com.br/secoes/estil/estil2.php

$4^{\circ}$ passo: Agora o grupo deverá criar um anúncio publicitário sobre um produto inédito. E muito importante que vocês escolham com cuidado o público-alvo do produto, pois isso facilitará a escolha dos recursos visuais do anúncio.

\section{ATENÇÃO!}

Lembrem-se de que o anúncio publicitário deve conter um título bem atraente, um produto inédito e, no mínimo, o uso de dois mecanismos estilísticos.

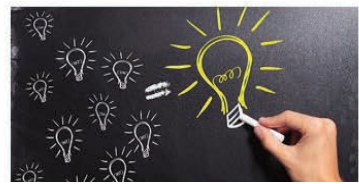

FIGURA 3 - Modelo de Processo e Recursos (Fonte: ZANONI, R.C, 2018) 


\section{AVALIAÇÃO}

O anúncio publicitário será avaliado de acordo com os seguintes critérios: Surpresa e Novidade; Qualidade dos argumentos de persuasão; Estética;

Gramática e Ortografia.

A verificação será coletiva e o grupo será classificado dentro da categoria correspondente, conforme os pontos obtidos:

Aprendiz $=1$ ponto

Profissional $=2$ pontos

Mestre $=3$ pontos

\begin{tabular}{|c|c|c|c|}
\hline Fatores & Aprendiz & Profissional & Mestre \\
\hline $\begin{array}{l}\text { Surpresa e } \\
\text { Novidade }\end{array}$ & $\begin{array}{l}\text { O produto } \\
\text { apresentado não é } \\
\text { novo no mercado. }\end{array}$ & $\begin{array}{l}\text { O produto é novo, mas } \\
\text { não houve surpresa na } \\
\text { apresentação do } \\
\text { anúncio. }\end{array}$ & $\begin{array}{c}\text { O produto e a } \\
\text { apresentação são } \\
\text { inéditos no mercado! }\end{array}$ \\
\hline $\begin{array}{l}\text { Qualidade dos } \\
\text { argumentos de } \\
\text { persuasão }\end{array}$ & $\begin{array}{l}\text { Nẫo possui } \\
\text { argumentos de } \\
\text { persuasão. }\end{array}$ & $\begin{array}{l}\text { O anúncio tem alguns } \\
\text { elementos de } \\
\text { persuasão. }\end{array}$ & $\begin{array}{l}\text { A publicidade é } \\
\text { extremamente } \\
\text { persuasiva! }\end{array}$ \\
\hline $\begin{array}{c}\text { Estética } \\
\text { (aparência do } \\
\text { material } \\
\text { produzido) }\end{array}$ & $\begin{array}{l}\text { O anúncio não possui } \\
\text { atributos estéticos } \\
\text { atrativos. }\end{array}$ & $\begin{array}{l}\text { O anúncio apresenta } \\
\text { falhas em relação aos } \\
\text { atributos estéticos. }\end{array}$ & $\begin{array}{l}\text { O anúncio está } \\
\text { impecável quanto aos } \\
\text { atributos estéticos! }\end{array}$ \\
\hline $\begin{array}{c}\text { Gramática e } \\
\text { Ortografia }\end{array}$ & $\begin{array}{l}\text { O trabalho apresenta } \\
\text { muitos problemas de } \\
\text { gramática, ortografia, } \\
\text { coesão e coerência. }\end{array}$ & $\begin{array}{l}\text { O trabalho apresenta } \\
\text { poucos problemas em } \\
\text { relação à escrita. }\end{array}$ & $\begin{array}{c}\text { O trabalho está perfeito } \\
\text { e não apresenta } \\
\text { problemas na escrita! }\end{array}$ \\
\hline
\end{tabular}

FIGURA 4 - Modelo de Avaliação (Fonte: ZANONI, R.C, 2018)

\section{CONCLUSÃO}

Ao concluir esse projeto, esperamos que vocês sejam capazes de:

- Compreender o conceito de Estilística;

- Identificar os recursos de expressividade como ferramentas de estilo;

- Diferenciar publicidade, anúncio e marketing;

- Adquirir a técnica de produção de um anúncio publicitário;

- Treinar os processos de leitura e escrita na Web;

- Aprender a trabalhar em equipe de maneira colaborativa;
Agora, o que vocês acham de verificarmos esses recursos em músicas? O endereço abaixo traz um vídeo bem interessante sobre as Figuras de linguagem e a Música. https://www.youtube.com/watch?v=8QsTduTAGQI

FIGURA 5 - Modelo de Conclusão (Fonte: ZANONI, R.C, 2018) 


\section{CRÉDITOS}

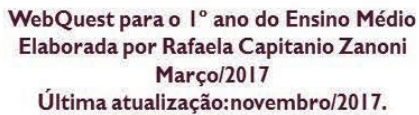

Fontes consultadas:

http://guiadoestudante.abril.com.br/profissoes/publicidade-epropagandal

http://www.sigmaquadrado.com/newsletter/arquivo/comofazeruman unciopublicitariodesucesso.htm

https://www.estudokids.com.br/anuncio-publicitário/

http://brasilescola.uol.com.br/redação/anuncio-publicitário.htm

https://www.todamateria.com.br/linguagem-publicitaria/

http://português.uol.com.br/gramatica/conceito-estilistica.html

http://mundoeducacao.bol.uol.com.br/gramatica/figuras-linguagem3.htm

http://www.figuradelinguagem.com/ https://rachacuca.com.br/educação/português/figuras-de-linguagem/ http://www.soportugues.com.br/secoes/estil/estil2.phphttps:/www. youtube.com/watch? $v=8$ Q ST TUTAGQI

\section{Imagens utilizadas:}

https://oficinadacriacaodot.com.wordpress.com/category/publicidad e-e-propagandal

http://www.agendor.com.br/blog/como-avaliar-o-desempenho-deum-funcionário/

http://fernandabelem.com.br/musica-com-o-nome-fernanda/ http://www.evef.com.br/artigos-e-noticias/administração-demarketing/240-o-conceito-de-publicidade

FIGURA 6 - Modelo de Créditos (Fonte: ZANONI, R.C, 2018)

\section{CONSIDERAÇÕES FINAIS}

Diante do exposto, é possível tecer algumas considerações acerca dessa metodologia educacional tão valiosa para o ensino-aprendizagem do século XXI.

Verificamos que os processos de leitura e escrita em ambiente digital são explorados por meio das WebQuests e contemplam o trabalho em grupo, de modo cooperativo e colaborativo, uma das mais relevantes características da ferramenta educacional de Dodge (1995).

As atividades devem ser repensadas e modificadas para atingir os alunos da contemporaneidade, seja nas aulas de Língua Portuguesa, seja nas demais atividades sob a 
responsabilidade da escola. Os alunos são estimulados a depreender sentidos a partir das muitas semioses contidas nos textos multimodais e a WebQuest é uma ferramenta que pode auxiliar os aprendizes a trabalharem com a multimodalidade textual no processo de aquisição dos multiletramentos.

Diante dessas reflexões, acreditamos que a WebQuest, metodologia de ensino que utiliza a navegação na internet como estratégia de construção do conhecimento colaborativo, tem muito a contribuir aos lautores, leitoresautores do século XXI, possibilitando uma multiplicidade de trocas e interações entre os alunos, a partir do ciberespaço. Dessa forma, a inserção da WebQuest em sala de aula é interessante para construirmos uma sociedade que pense digitalmente, que saiba emitir sua opinião crítica a partir da busca de informações confiáveis e que aprenda que o trabalho em equipe é essencial na construção do aprendizado.

\section{REFERÊNCIAS}

ABAR, C. A. A. P.; BARBOSA, L. M.(2008). WebQuest: um desafio para o professor. São Paulo: Avercamp. p.100

AZEVEDO, R. S.(2013). Ler e navegar.gov.br: experiências de interação em um Portal da Transparência. (Dissertação - Mestrado). Belo Horizonte: UFMG.

COSCARELLI, C. V.(2016) (Org.). Tecnologias para aprender. São Paulo: Parábola Editorial, p.192

DODGE, B. (1995). WebQuests: A Technique for Internet - Based Learning. The Distance Educator 1(2). Jarbas Novelino Barato (Trad.). 
KENSKI, V. M. (2012). Educação e tecnologias: o novo ritmo da informação. 8.ed. Campinas, SP: Papirus, p.141

RIBEIRO, A. E. (2012). Novas tecnologias para ler e escrever: algumas ideias sobre ambientes e ferramentas digitais na sala de aula. Belo Horizonte: RHJ. p.136

ROCHA, L. R. (2007). A concepção de pesquisa no cotidiano escolar: possibilidades de utilização da metodologia webquest na educação pela pesquisa (Dissertação - Mestrado em Educação) - Universidade Federal do Paraná. Curitiba.

ROJO, R. (2013) (Org.). Escola conectada: os multiletramentos e as TICs. São Paulo: Parábola Editorial, p.216.

SILVA, E. M. O. (2008). A WebQuest na internet: o novo material didático. Revista da FAE, 11, 79-86.

Denise Salim Santos possui graduação em Língua Portuguesa/Literaturas da Língua Portuguesa pela Universidade Gama Filho (1975), graduação em Pedagogia pela Sociedade Universitária Augusto Motta (1977), mestrado em Língua Portuguesa pela Universidade do Estado do Rio de Janeiro (2000) e doutorado em Curso de Mestrado e Doutorado da UERJ pela Universidade do Estado do Rio de Janeiro (2008). Atualmente é Professor Adjunto de Língua Portuguesa na Universidade do Estado do Rio de Janeiro (UERJ). Atua nos Cursos de Pós-graduação em Língua Portuguesa: Especialização e Mestrado (UERJ). Tem experiência na área de Letras, com ênfase em Língua Portuguesa, atuando principalmente nos seguintes temas: língua portuguesa, linguagem, linguística, léxico e língua escrita.

Rafaela Capitanio Zanoni Possui graduação em Letras com habilitação em Português e Literaturas de Língua Portuguesa pela Universidade Estácio de Sá (2012). Pós-graduação em Letramento(s) e Práticas Educacionais pelo CEFET/RJ. Mestra em Língua Portuguesa pela Universidade do Estado do Rio de Janeiro - UERJ (2018). 